Brit. J. industr. Med., 1960, 17, 52.

\title{
A STUDY OF HEAT STRESS IN EXTREMELY HOT ENVIRONMENTS, AND THE INFRA-RED REFLECTANCE OF SOME POTENTIAL SHIELDING MATERIALS
}

\author{
BY
}

\author{
CHARLES E. LEWIS, RICHARD F. SCHERBERGER, and FRANKLIN A. MILLER \\ From the Laboratory of Industrial Medicine, Eastman Kodak Company, Rochester, New York
}

(RECEIVED FOR PUBLICATION JUNE 22, 1959)

In the course of evaluating industrial heat exposures, three very hot environments having heat stress indices over 300 have been analysed by the techniques of Haines and Hatch (1952) and Belding and Hatch (1955). In addition, pulse and oral temperature measurements were made on three subjects exposed to these environments. These studies indicate that the methods of Haines and Hatch and Belding and Hatch tend to err on the side of safety when applied to very hot areas. Safe exposure times calculated by their techniques are approximately one-third those determined by either physiological measurement or by safe tolerance curves recommended by the American Society of Heating and Ventilation Engineers (ASHVE).

The intelligent use of shielding as a method of protecting workers from radiant heat requires a knowledge of the infra-red reflectance curves of common industrial materials. Nineteen such curves are included.

Numerous attempts have been made to translate the physical parameters of a hot environment into a physiological index which may be utilized to project the effects of that environment upon man.

One of the most successful of these attempts has been that of Belding and Hatch (1955) based upon previous work by Haines and Hatch (1952). The heat stress index which has been developed by these authors utilizes the wet-bulb, dry-bulb, and globe temperatures, the air velocity of the environment, and the metabolic heat load produced by the activity of the man.

Modern industry has created many environments which can only be classified as very hot. The heat stress index of these environments, as determined by the method of Belding and Hatch, will often be over 100 and may occasionally exceed 1,000 . By definition, a Belding-Hatch heat stress index of 100 describes the maximum heat stress to which a young, healthy, acclimatized male can be subjected for eight hours without developing adverse physiological changes.

The applicability of this index to such very hot environments is not known. This report describes the analysis and study of three hot environments with heat stress indices ranging from 395 to 524 and details an attempt to analyse them by the Belding and Hatch technique.
Radiant heat frequently represents a significant percentage of the total heat load imposed by a hot environment. This poses the practical problem of shielding workers from infra-red energy. Of particular interest is the reflectance of various materials and clothing used or worn in the plant. The physician or hygienist investigating a hot process is often asked about the protective value of certain clothing or shielding. To help answer these questions, the infra-red reflecting properties of many different materials have been measured with a recording spectrophotometer. A brief report of the data so obtained constitutes the second section of this paper.

\section{Methods}

The physical characteristics of the environment were measured with a 24-hour recording device constructed in this laboratory and modelled upon a prototype developed by Dunn and McMahon at Corning Glass Works, Corning, New York (Fig. 1). The globe, drybulb, and wet-bulb temperatures are measured with the use of thermocouples and recorded graphically on 24-hour charts ("auto-lite" model 1000-A recording thermometers*). A small blower (Fasco No. 50747-3N) $\dagger$ stationed in the base of the enclosure assures a constant

* Electric Auto-lite Co., Industrial Thermometer Div., Toledo 1, Ohio.

† Fasco Ind. Inc., 255 N. Union St., Rochester 2, New York. 


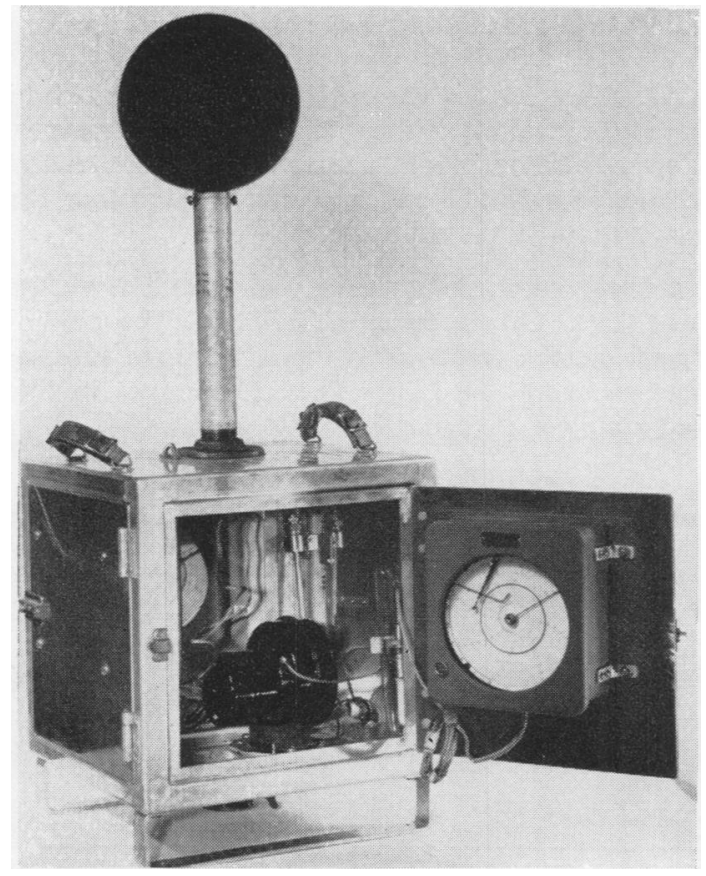

FIG. 1.-The 24-hour recording device.

air flow past the dry-bulb and wet-bulb elements. The box is constructed of aluminium to minimize the effect of radiant heat upon the dry bulb. All thermometers were checked for proper adjustment by comparison with an aspiration type psychrometer which utilized Taylor Instrument's "binoc" certified thermometers for wet- and dry-bulb temperatures. The black globe was fabricated from an 8-in. diameter, all copper, spherical, seamless float having an external lug 1 in. high which is $\frac{1}{2}$ in. coupling (standard pipe thread). This float was painted with dull black lacquer and dusted with carbon black while wet and was mounted with the centre 16 in. above the top surface of the box. In the calculation of mean radiant temperature $\left(T_{w}\right)$ from globe temperature $\left(T_{g}\right)$, a correction coefficient of $0 \cdot 164$ was used to compensate for the 8-in. diameter globe.

Air velocity was measured with the use of the model 60 "anemotherm" air meter (Anemostat Corporation of America).

Body temperatures were recorded orally before and after exposure to heat. Subjects neither smoked, drank, nor ate for one-half hour before the onset of temperature recording. Blood pressures were recorded in the left arm, utilizing an aneroid sphygmomanometer.

The Beckman DK-2 spectroreflectometer will be discussed more completely in Section II of this paper.

Subjects were unacclimatized, healthy males ranging in age from 30 to 40 and in weight from 79 to $82 \mathrm{~kg}$.

Clothing worn by subjects consisted of shoes and socks, short-sleeved cotton undershirt, cotton undershorts, and light trousers.

\section{Results: Section I}

Using the environmental data given in Table 1 and the Belding-Hatch equations, heat stress indices of 524,397 , and 395 were calculated.

Area at Heat Stress Index 524.-Table 2 lists the physiological changes noted in three subjects after exposures of 15,20 , and 15 minutes in the area (A) found to have a heat stress index of 524 .

All subjects noted an onset of sweating three to four minutes after entering the area. A feeling of

TABLE 1

SUMMARY OF ENVIRONMENTAL STUDIES IN HOT AREAS

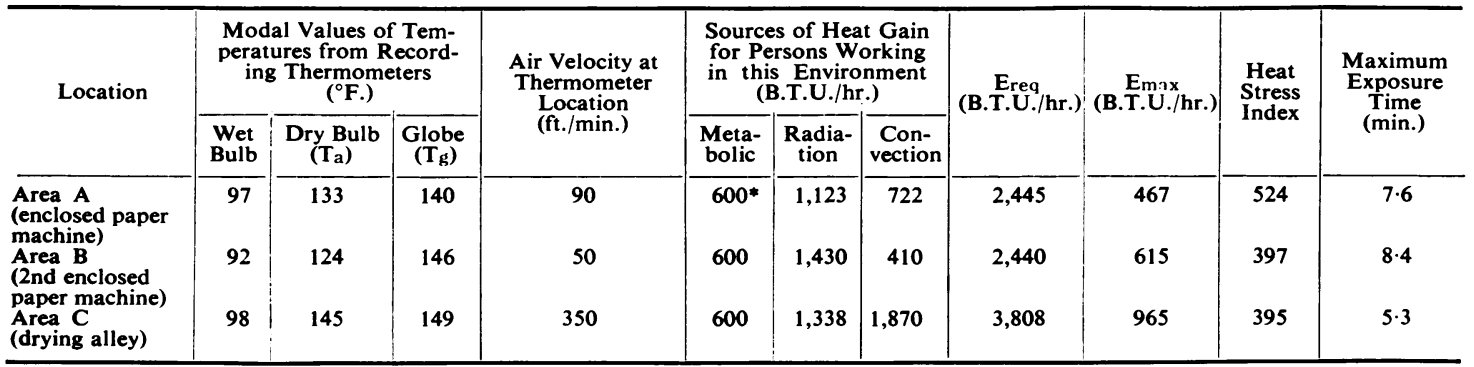

*600 B.T.U./hr. represents the metabolic heat of light, standing work.

$$
\begin{aligned}
C & =2 \sqrt{V}\left(t_{a}-95\right) \\
E_{\max } & =10.3 V^{0 \cdot 4}\left(42-V P_{a}\right)
\end{aligned}
$$

$$
\begin{aligned}
& \mathrm{R}+\mathrm{C}=(22+2 \sqrt{\mathrm{V}})\left(\mathrm{t}_{\mathrm{g}}-95\right) \\
& \mathrm{HSI}=\frac{\mathrm{E}_{\mathrm{req}}}{\mathrm{E}_{\max }} \times 100
\end{aligned}
$$

Maximum permissible exposure (minutes) $=\frac{250}{E_{\mathrm{req}}-E_{\max }} \times 60$

ta = ambient temperature.

$\mathrm{V}=$ air speed in feet per minute.

$t_{\mathrm{g}}=$ black globe temperature.

$\mathbf{V P a}_{\mathbf{a}}=$ vapour pressure of the air in millimetres of mercury. 
TABLE 2

PHYSIOLOGICAL CHANGES OBSERVED IN AREA A (ENCLOSED PAPER MACHINE) WITH HEAT STRESS INDEX OF 524

\begin{tabular}{l|c|c|c}
\hline & Subject 1 & Subject 2 & Subject 3 \\
\cline { 2 - 2 } Exposure time (min.) & 15 & 20 & 15 \\
Pulse rate before & 88 & 90 & 68 \\
Pulse rate after & 114 & 120 & 90 \\
Pulse rate change & +26 & +30 & +22 \\
Temperature ( $\left.{ }^{\circ} \mathrm{F}.\right)$ before & $98 \cdot 5$ & $99 \cdot 2$ & $98 \cdot 5$ \\
Temperature ( $\left.{ }^{\circ} \mathrm{F}.\right)$ after & $99 \cdot 4$ & $100 \cdot 0$ & $99 \cdot 3$ \\
Body temperature change & $+0 \cdot 9$ & $+0 \cdot 8$ & $+0 \cdot 8$ \\
Blood pressure before & $142 / 90$ & $120 / 90$ & $120 / 70$ \\
Blood pressure after & $144 / 94$ & $118 / 84$ & $128 / 74$ \\
Blood pressure change & $+2 /+4$ & $-2 /-6$ & $+8 /+4$ \\
\hline
\end{tabular}

moderate fatigue was noted by all for approximately two to four hours after the exposure to heat. During the time of exposure, subjects walked slowly back and forth within the area so that a metabolic heat production of about 600 B.T.U./hr. was probable.

It will be noted that the pulse rate rose from 22 to 30 beats per minute and oral temperature increased $0.8^{\circ} \mathrm{F}$. in two subjects exposed for 15 to 20 minutes and $0.9^{\circ} \mathrm{F}$. in the subject exposed 15 minutes. There was very little change in diastolic or systolic blood pressures.

Area at Heat Stress Index 397.--Physical measurements in area $\mathbf{B}$ are given in Table 1.

Table 3 presents the physiological changes occurring in three subjects exposed to this environment with a heat stress index of 397.

TABLE 3

PHYSIOLOGICAL CHANGES OBSERVED IN AREA B (SECOND ENCLOSED PAPER MACHINE) WITH HEAT STRESS INDEX OF 397

\begin{tabular}{l|c|c|c}
\hline & Subject 1 & Subject 2 & Subject 3 \\
\cline { 2 - 4 } Exposure time (min.) & 15 & 30 & 22 \\
Pulse rate before & 88 & 86 & 72 \\
Pulse rate after & 128 & 148 & 120 \\
Pulse rate change & +40 & +62 & +48 \\
Temperature ( ${ }^{\circ}$ F.) before & 98.0 & 97.9 & $98 \cdot 0$ \\
Temperature ( ${ }^{\circ}$.) after & 99.6 & $101 \cdot 6$ & $99 \cdot 7$ \\
Body temperature change & +1.6 & $+3 \cdot 7$ & $+1 \cdot 7$ \\
Blood pressure before & $130 / 82$ & $110 / 70$ & $120 / 78$ \\
Blood pressure after & $148 / 92$ & $108 / 62$ & $134 / 66$ \\
Blood pressure change & $+18 /+10$ & $-2 /-8$ & $+14 /-12$ \\
\hline
\end{tabular}

Subject 1, who was exposed to this environment 15 minutes, sustained an increase of $1.6^{\circ} \mathrm{F}$. in temperature and of 40 beats per minute in pulse rate. Both diastolic and systolic blood pressures rose 10-20 millimetres. Subject 3 remained in the same environment for a total of 22 minutes. His temperature rose $1.7^{\circ} \mathrm{F}$, with a concomitant pulse increase of 48 beats per minute. His systolic blood pressure rose 14 millimetres, while his diastolic pressure fell 12 millimetres. Subject 2 remained in the environment for 30 minutes. His oral temperature was elevated $3 \cdot 7^{\circ} \mathrm{F}$; ;is pulse rose 62 beats per minute. His systolic blood pressure remained almost unchanged and there was an $8 \mathrm{~mm}$. decrease in his diastolic blood pressure.

All subjects noted the onset of sweating in two to three minutes after the start of their exposure. Subject 2 also noted mild nausea after 15 minutes and became somewhat weak and dizzy just before the termination of his exposure.

Area at Heat Stress Index 395.-Data from the third Area (C) are given in Table 1. The physiological change recorded in the same three subjects after exposures of 15,17 , and 20 minutes in this area are given in Table 4.

TABLE 4

PHYSIOLOGICAL CHANGES OBSERVED IN AREA C (DRYING ALLEY) WITH HEAT STRESS INDEX OF 395

\begin{tabular}{l|c|c|c}
\hline & Subject 1 & Subject 2 & Subject 3 \\
\cline { 2 - 4 } Exposure time (min.) & 15 & 17 & 20 \\
Pulse rate before & 90 & 82 & 76 \\
Pulse rate after & 124 & 110 & 104 \\
Pulse rate change & +34 & +28 & +28 \\
Temperature ( ${ }^{\circ}$ F.) before & $98 \cdot 2$ & $98 \cdot 6$ & $98 \cdot 4$ \\
Temperature ( ${ }^{\circ}$ F.) after & $100 \cdot 2$ & $100 \cdot 3$ & $100 \cdot 5$ \\
Body temperature change & $+2 \cdot 0$ & $+1 \cdot 7$ & $+2 \cdot 1$ \\
Blood pressure before & $134 / 76$ & $100 / 78$ & $106 / 68$ \\
Blood pressure after & $148 / 108$ & $104 / 74$ & $148 / 60$ \\
Blood pressure change & $+14 /+32$ & $+4 /-4$ & $+42 /-8$ \\
\hline
\end{tabular}

The physiological changes range from an increase in body temperature of $1.7^{\circ} \mathrm{F}$. in 17 minutes (Subject 2) to a $2 \cdot 1^{\circ} \mathrm{F}$. rise (Subject 3) after 20 minutes' exposure. Pulse rate increases were from 28 beats to 34 beats per minute.

\section{Discussion}

The Belding and Hatch approach to the physiological analysis of hot environments has proved very successful in situations where the heat stress index has been below 100. Its application to areas where the calculated index greatly exceeds this number might be expected to have certain shortcomings in view of the derivation of the approach itself.

Most of the information and studies which were considered in the evolution of the Belding-Hatch index concerned men in environments where the dry-bulb temperature did not exceed $120^{\circ} \mathrm{F}$. and the wet-bulb temperature was below $96^{\circ} \mathrm{F}$. It will be apparent from the formula (HSI $=100 \mathrm{E}_{\mathrm{req}}$ / $\left.E_{\max }\right)$ that as the capacity for evaporative cooling approaches zero, the heat stress index will approach infinity. Its use in environments where this does, in fact, occur is obviously precluded.

The projection or calculation of permissible exposure within an area having a certain heat stress index is ultimately based upon the original definition of a safe tolerance limit. This has been defined as the time required to raise the pulse $40-45$ beats per minute and the body temperature $2^{\circ} \mathrm{F}$. Suggested 
methods of evaluating hot environments are based upon the precept that physiological changes in excess of these must be avoided (Hatch, 1958).

For the experiments described herein, two methods of estimating safe exposure times were used. The first employed the tolerance contours resulting from joint studies by the American Society of Heating and Ventilating Engineers (ASHVE) and the U.S. Bureau of Mines during the years 1922-1926 (Hatch, 1958). These curves relate permissible exposure time within an environment to the dry-bulb temperature and relative humidity of that environment; permissible exposure time is based upon measured changes in rectal temperature and heart rate. The second method of estimating permissible exposure times was that of Belding and Hatch, which utilizes an estimate of the time required to cause a $2^{\circ} \mathrm{F}$. increase in body temperature, and is based upon the calculated values for $E_{\text {req }}$ and $E_{\max }$ of the environment.

A comparison of results obtained with these two methods of estimating permissible exposure times is pertinent. In areas A and B, the ASHVE curves gave permissible exposure times of approximately 20 minutes, with 15 minutes being the predicted time in area $C$. In contrast, the Belding and Hatch approach indicated a permissible exposure time of eight minutes in areas $\mathbf{A}$ and $\mathbf{B}$ and five minutes in area $C$. Physiological measurements made in our subjects during their actual exposure in these areas indicated that the ASHVE estimates were relatively correct. Since these latter estimates are themselves based upon physiological data, this agreement was to be expected.

The foregoing comparison indicates that the estimates obtained by the Belding-Hatch method are about one-third those which physiological measurements and the ASHVE curves indicate would actually be permissible. Because the BeldingHatch technique appears to err on the side of safety, no hazardous situations should arise from its use. This discrepancy may be related to a critical assumption made by Belding and Hatch in constructing their equations. Much of the data used in deriving the heat stress index has been based on nude subjects. The assumption was made that the wearing of light clothing will have little influence upon the heat exchange of the body by conduction and convection. This assumption is evidently valid in environments in which the heat stress index is below 100 , as is evidenced by the applicability of the index in such situations (Turner, 1957). However, when the thermal gradient between skin and environmental temperature is markedly increased, the wearing of even light clothing appears to have a significant effect upon the index value.
The quantity of heat transferred to man from the environment is dependent upon the thermal conductivity of both atmosphere and clothing and upon the thickness of the still air layers. The insulating effect of a still air layer is proportional to its thickness and inversely related to the square root of the ambient air velocity (Newburgh, 1949). When the difference between air and skin temperatures is small, the reduction in heat transfer due to the insulating properties of clothing is relatively insignificant. However, as the skin-air thermal gradient increases, the still air and clothing strata may insulate the body from a significant quantity of environmental heat.

When applying this mode of heat analysis, one must be cautious not to equate heat stress indices with permissible exposure times. Note the following theoretical example, comparing two situations with different $E_{r e q}$ and $E_{\max }$ but equal heat stress indices.

\begin{tabular}{l|c|c}
\hline & 1 & 2 \\
\cline { 2 - 3 } Ereq (BTU/hr.) & 1,000 & 4.000 \\
Emax (BTU/hr.) & 500 & 2.000 \\
Heat stress index & 200 & 200 \\
Permissible exposure time (min.) & 30 & $7 \cdot 5$ \\
\hline
\end{tabular}

The heat stress indices appear to indicate that the two areas are equally hot. In fact, area 2 is four times as hot as area 1 in so far as its effect upon an exposed individual is concerned. The heat stress index is based on the ratio of $E_{\text {req }}$ to $E_{\max }$ whereas the permissible exposure time is based on the ratio of 250 to the absolute difference between $\mathrm{E}_{\mathrm{req}}$ and $\mathrm{E}_{\max }$.

In exposures of short duration, the change in body temperature should be the most critical measurement of heat load. The pulse and blood pressure responses can be influenced by other non-thermal factors such as discomfort and anxiety. The variation in pulse rate change is obvious within and between the three areas. Other reports (Bass and Henschel, 1956) have cited the variability in blood pressure responses seen in thermal stress.

The correspondence between the permissible time estimated from the ASHVE safe tolerance contours and those actually found in the field should not be surprising. They both use the same physiological criteria.

The information obtained by physiological measurements in hot environments can be used to outline medical controls necessary to insure the health of the workers who may of necessity be required to work briefly in such environments. These medical controls include the limiting of exposure to young, healthy males who are examined by a physician at least every six months. The 
maximum time spent by any one individual in the environment should be limited to a time period less than that found to cause an elevation of body temperature of $2^{\circ} \mathrm{F}$. and a pulse increase of 45 beats per minute. A rest period should be provided for workers who have sustained an exposure to heat immediately after their exposure.

When job requirements are such that the time required to do the necessary tasks exceeds that of the permissible exposure, it would be necessary to utilize more than one individual, or else provide some type of direct personal protection for the individual, such as reflective clothing or air supplied suits.

While the information obtained in such physiological measurements is on men unacclimatized to heat, this would seem to be appropriate. It is highly unlikely that individuals sustaining only heat exposure of this degree would ever become acclimatized, for this, by definition, requires the performance of work within hot environments.

\section{Section II}

One of the advantages of the Belding and Hatch analysis of hot environments is that it yields values for the individual components of heat stressradiation, convection, and conduction heat gainsand includes an estimate of evaporative heat losses.

In areas $A$ and $B$, described in Section I, approximately $50 \%$ of the total heat burden incident upon an individual is due to radiation. To cool a worker in such an area, it is appropriate to apply methods which would decrease the radiation gain by reducing infra-red radiation at its source, or by reflecting it from the individual.

The quantity and wavelength distribution of infra-red energy which is radiated from a body is directly dependent upon the temperature of that body. Wien's law indicates that a body with a surface temperature of $1,200-1,400^{\circ} \mathrm{C}$. will produce infra-red radiation with a mean wavelength of approximately 1.8 microns. The distribution curve of infra-red radiation from bodies with a surface temperature of about $300^{\circ} \mathrm{C}$. is very flat with a mean at approximately 5 microns (Duff, 1937).

Information on the percentage reflectance at different wavelengths of infra-red energy by certain materials has been limited to the data originally derived by Coblentz (National Bureau of Standards) in the period 1917-1920 (Coblentz, 1920). Measurements of absolute infra-red reflectance are difficult and have been abandoned by many groups of investigators.

Within the past five years, an instrument has been developed which makes it possible to measure relative reflectance of radiation from the ultraviolet range up to 2.7 microns. This instrument (Beckman DK-2 spectroreflectometer) utilizes a tungsten source for the infra-red energy. Two incident monochromatic beams are used. One is

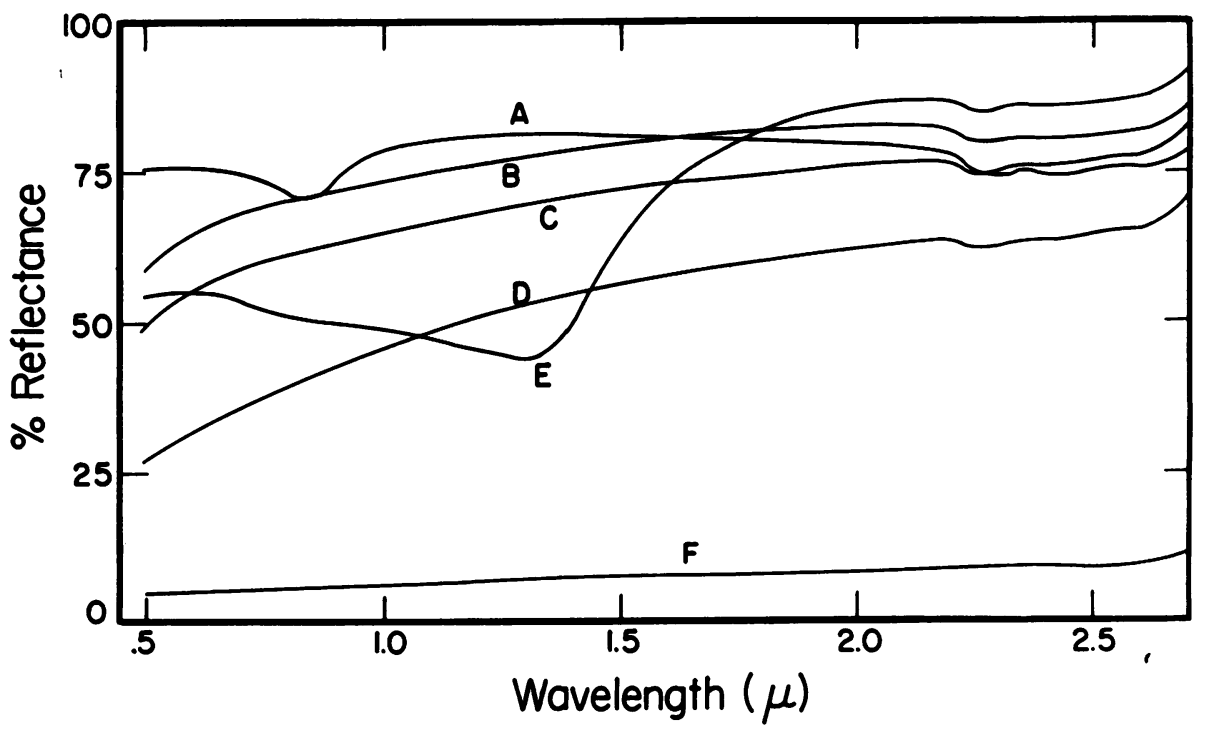

Fig. 2

$\mathbf{A}=$ aluminium foil.
$\mathbf{B}=$ buffed nickel plate.
$\mathbf{C}=$ nickel plate.
$\mathbf{D}=$ electroless nickel plate.

$\mathbf{E}=$ cadmium plate.

$\mathbf{F}=$ black paint on nickel. 
directed at the reflectance standard, magnesium oxide; the other is incident on the material to be studied. The reflected energy is collected by the use of an integrating sphere and a comparison between the magnesium oxide reflectance and the unknown is recorded on the chart. The magnesium oxide reflects about $95 \%$ of infra-red energy in the range 1.0 to 2.5 microns wavelengths. To derive "absolute" reflectance values, a suitable correction must be made.

Figs. 2 to 6 demonstrate the reflectance curves of various metals, painted surfaces, and fabrics. The

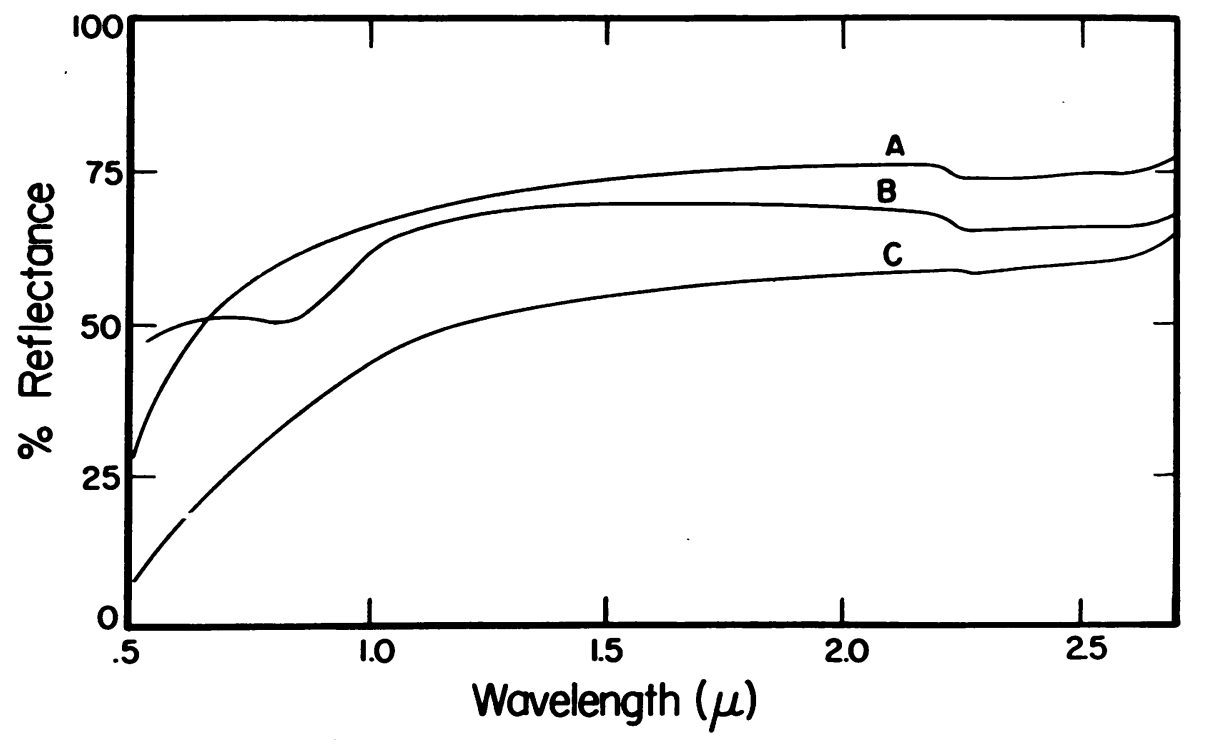

FIG. 3

$\mathbf{A}=$ brass.

$\mathbf{B}=$ aluminium.

C $=$ copper.

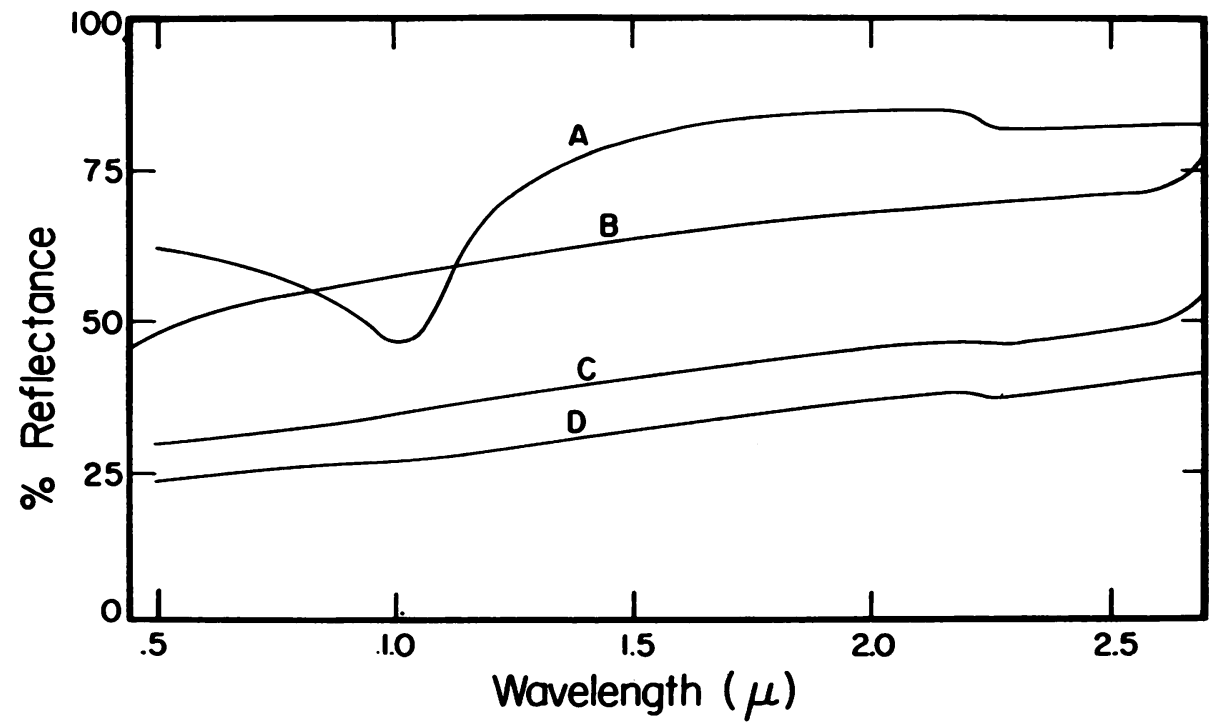

Fig. 4

$A=$ galvanized steel.

B $=$ stainless steel.

C = galvaneal.

D $=$ steel. 
percentage reflectance at several specific wavelengths has been tabulated in Table 5. All materials studied, including fabrics, were backed by a black cloth to eliminate any reflection of radiation which might penetrate through the thickness of material.

It will be noted that, with respect to their per- centage reflectance of wavelengths above $2 \cdot 0$ microns, materials tested rank in the following descending order: cadmium plate, galvanized steel, buffed nickel plate, aluminium foil. Industry, giving consideration to purchase price and ease of maintenance, has adopted aluminium as the preferred

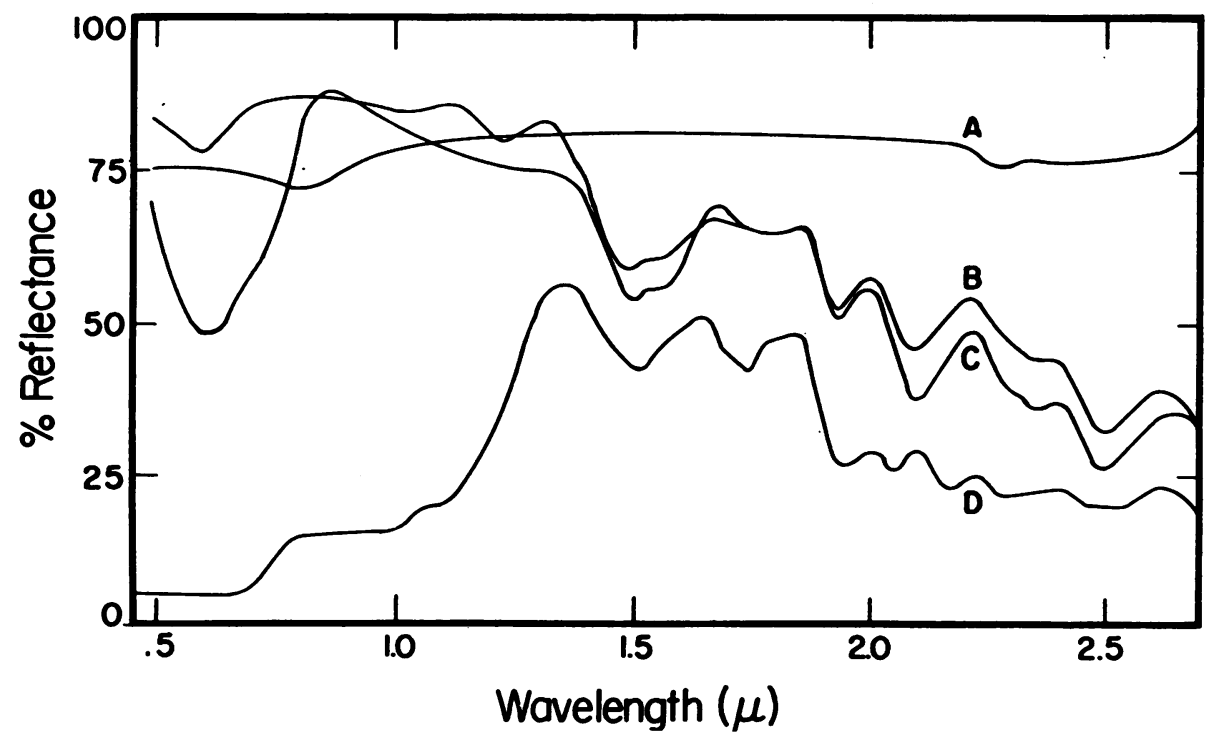

Fig. $5 \quad \mathrm{~A}=$ aluminium coating reflecting fabric. $\mathbf{B}=$ blue oxford cloth.

$\mathrm{C}=$ white broadcloth

D = charcoal grey flannel cloth.

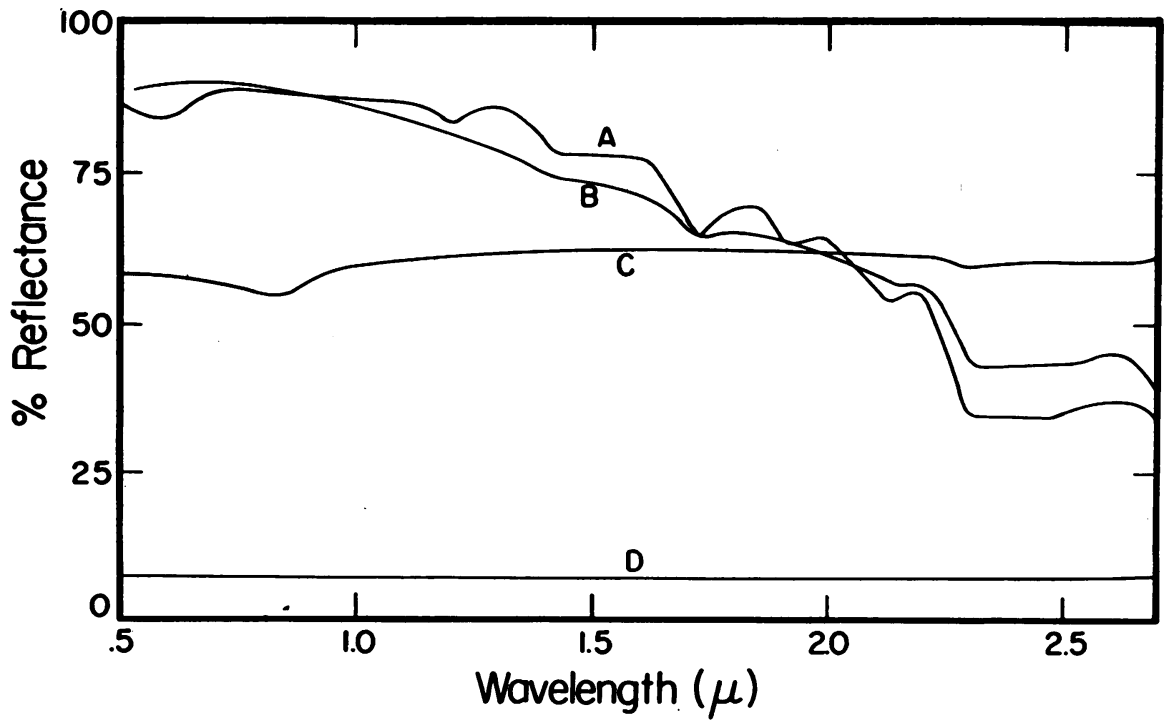

FIG. 6

$A=$ white rubber base enamel.

$\mathbf{C}=$ aluminium interior varnish.

B = white machine enamel on masonite panel.

$\mathbf{D}=$ flat black enamel. 
shielding material. While the white fabric and blue fabric are quite efficient reflectors in the near infra-red region of 1 micron, their reflectant properties decrease considerably as the wavelength exceeds 2 microns.

TABLE 5

PERCENTAGE REFLECTANCE OF VARIOUS MATERIALS AT CERTAIN WAVELENGTHS

\begin{tabular}{l|c|c|c|c|c}
\hline \multicolumn{1}{c|}{ Material } & \multicolumn{3}{|c}{$\begin{array}{c}\text { Percentage Reflectance at } \\
\text { Certain }\end{array}$} \\
& \multicolumn{3}{|c|}{ Wavelengths } \\
\hline Nickel plate-buffed & $0 \cdot 5 \mu$ & $1 \cdot 0 \mu$ & $1 \cdot 5 \mu$ & $2 \cdot 0 \mu$ & $2 \cdot 5 \mu$ \\
\hline Electroless nickel plate & 58 & 72 & 79 & 82 & 81 \\
Nickel plate & 27 & 44 & 56 & 62 & 65 \\
Black paint on nickel & 49 & 64 & 71 & 76 & 77 \\
Cadmium plate & 4 & 5 & 7 & 8 & 8 \\
Aluminium foil & 54 & 49 & 62 & 86 & 87 \\
Aluminium & 76 & 78 & 81 & 80 & 81 \\
Brass & 46 & 62 & 69 & 69 & 66 \\
Copper & 28 & 66 & 74 & 76 & 75 \\
Steel & 8 & 44 & 55 & 58 & 60 \\
Stainless steel & 23 & 27 & 32 & 36 & 39 \\
Galvanized steel & 45 & 58 & 63 & 68 & 71 \\
Galvaneal & 62 & 46 & 79 & 85 & 82 \\
Aluminium varnish (interior) & 29 & 35 & 40 & 45 & 48 \\
White machine enamel on & 58 & 59 & 62 & 62 & 60 \\
$\quad$ masonite & 88 & 87 & 78 & 64 & 43 \\
White rubber base enamel & 91 & 85 & 74 & 61 & 44 \\
Flat black enamel & 7 & 7 & 7 & 7 & 7 \\
White shirt (close cotton weave) & 83 & 84 & 54 & 56 & 26 \\
Blue shirt (oxford cloth) & 70 & 82 & 59 & 58 & 32 \\
Charcoal grey flannel & 5 & 16 & 42 & 27 & 20 \\
Reflective hood & 75 & 78 & 81 & 81 & 77 \\
\hline
\end{tabular}

\section{Discussion}

It is not possible to relate the relative reflectance in the visible range (as observed with the naked eye) to the infra-red reflectance of the same material. The above figures offer several examples of this. Values obtained with the reflectance spectrophotometer are relative to a commonly used standard (magnesium oxide) and are not absolute values. This does not negate the instrument's usefulness. Such measurements can be used to design stationary and mobile shielding as well as personnel protective equipment.

\section{Conclusions}

Three hot environments with heat stress indices of 524, 397, and 395 (as calculated by the Belding and Hatch approach) have been studied. Physiological measurements on men exposed to these environments have been made in an effort to estimate safe exposure times. Observed responses corre- sponded well to those predictable from the safe tolerance contours obtained by the studies of the American Society of Heating and Ventilating Engineers and the U.S. Bureau of Mines. In contrast, the calculated safe exposure times derived by the method of Belding and Hatch were found to be approximately one-third those actually measured. It is probable that this difference (between the predicted and observed permissible exposure times) is proportional to the time required for an exposed individual's peripatetic micro-environment to equilibrate with the macro-environment. The time required to reach this state of thermal equilibrium is a function of the insulating properties of his clothing. It is apparent also that with heat stress indices over 100 , the simple index alone cannot provide an estimate of the safe tolerance time. Until further data are developed which make it possible to modify this index and extend it to areas such as described herein, it would seem advisable to rely upon physiological measurements as a means of evaluating the tolerance limits of very hot environments.

In Section II measurements are given on the relative reflectance of certain materials useful for shielding workers against infra-red radiation. The use of the reflectance spectrophotometer in obtaining measurements of reflectance at various wavelengths in the infra-red would seem useful in the pre-construction evaluation of equipment to be used in both mobile and stationary shielding and in personal protective equipment.

The authors are indebted to Mr. Frank Grum and Mr. Theodore Wightman, of the Eastman Kodak Company Research Laboratory, for performing the spectrophotometric measurements of infra-red reflectance.

\section{REFERENCES}

Bass, D. E., and Henschel, A. (1956). Physiol. Rev., 36, 128. Belding, H. S., and Hatch, T. F. (1955). Heating Piping, and Air Conditioning, August, pp. 129-136.

Coblentz, W. N. (1920), Bulletin No. 379, U.S. Bureau of Standards. Duff, A. W., ed. (1937), Physics, 8th ed., p. 273. Blakiston, Philadelphia.

Haines, G. F., and Hatch, T. (1952). Heating and Ventilating,

Hatch, T. F. (1958). In Industrial Hygiene and Toxicology, ed. Patty, F. A., 2nd ed., Vol. 1, p. 806, Interscience Publishers, New York

Newburgh, L. H. (1949). Physiology of Heat Regulation and the Science of Clothing. W. B. Saunders, Philadelphia.

Science of Clothing. W. B. Saunders, Philad
Turner, D. (1957). Brit. J. industr. Med., 14, 177. 